MKG-Chirurg 2018 $\cdot 11: 209-210$

https://doi.org/10.1007/s12285-018-0161-6

Online publiziert: 11. Juli 2018

(c) Springer Medizin Verlag GmbH, ein Teil von Springer Nature 2018

CrossMark

\section{B. Frerich}

Klinik und Poliklinik für Mund-, Kiefer- und Plastische Gesichtschirurgie, Universitätsmedizin Rostock Rostock, Deutschland

\section{Erratum zu: Therapie des kutanen malignen Melanoms im Kopf- Hals-Bereich}

\section{Ein Update}

\section{Erratum zu:}

MKG-Chirurg 2018.

https://doi.org/10.1007/s12285-018-

0147-4

In der Legende zu • Abb. 1a wurde leider ein sinnentscheidendes Komma vergessen.

Die richtige Abbildungslegende ist hier dargestellt.

Wir bitten, die korrekte Abbildungslegende zu beachten und den Fehler zu entschuldigen.

Die Redaktion

\section{Korrespondenzadresse}

Prof. Dr. Dr. B. Frerich

Klinik und Poliklinik für Mund-, Kiefer- und Plastische Gesichtschirurgie, Universitätsmedizin Rostock

Schillingallee 35, 18057 Rostock, Deutschland bernhard.frerich@med.uni-rostock.de 


\section{Erratum}
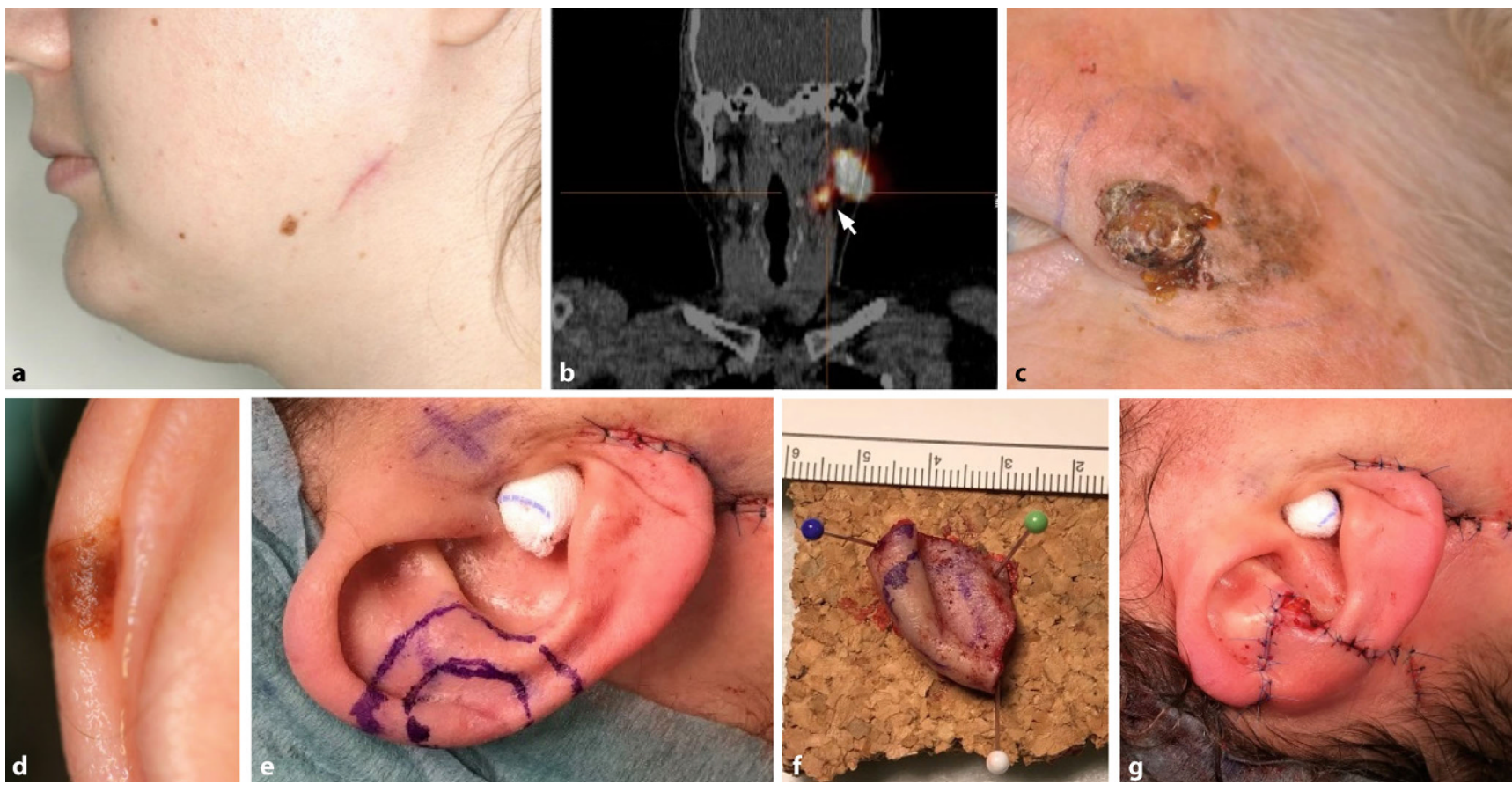

Abb. 1 a 23-jährige Patientin, Zuweisung nach diagnostischer Exzision alio loco (s. frische Narbe), non in sano, Histologie: Melanom Breslow 0,7 mm, nicht ulzerierend, klinisch und sonographisch kein Hinweis auf Lymphknotenmetastasierung, somit Stadium IA (T1a NO MO). Nachresektion mit $1 \mathrm{~cm}$ seitlichem Abstand, zur Tiefe im subkutanen Fettgewebe, Deckung durch Dehnungsplastik möglich. b Sentinel-Lymphknoten-Biopsie (SLNB) vor dem Hintergrund Patientenalter und non in sano Vorexzision durchgeführt (präoperatives SPECT/CT, Pfeil: uptake des Fazialis-LK).c 82-jährige Patientin, Melanom Breslow $5 \mathrm{~mm}$ ulzerierend, knapp in sano diagnostisch exzidiert. Diagnostik: Lymphknotensonographie, S100 B im Serum, PET/CT + MRT Kopf oder Ganzkörper-CT/-MRT. Resektion mit angestrebtem Abstand $2 \mathrm{~cm}$, zum Lidbereich darunter, SLNB (negativ), somit Stadium II C (T4b N0 M0). d Kleines Lentigo maligna-Melanom in einer Lentigo am Helixrand. Zunächst diagnostische Exzision mit 2 mm Sicherheitsabstand. Breslow-Dicke 0,3 mm, bereits R0, sonographisch kein Hinweis auf Metastasierung, Stadium I A. e SLNB (subaurikulär) in Absprache mit Patientin durchgeführt, Anzeichnung der definitiven Resektion mit $1 \mathrm{~cm}$ (äußere Markierung) um die Narbe der diagnostischen Exzision am Helixrand, mit knorpeliger Unterlagei. S. einer Keilresektion.f Resektat, g Beginn der Rekonstruktion in gleicher Sitzung. PET Positronenemissionstomographie, CT Computertomographie, MRT Magnetresonanztomographie 